\title{
PENGARUH PENYAMPAIAN INSTRUKSI, PERENCANAAN PEMBELAJARAN, DAN PENGETAHUAN YANG PROFESIONAL DENGAN MEDIASI KEPUASAN AKAN KARIR TERHADAP KINERJA DOSEN
}

\author{
Ignatius Jeffrey ${ }^{1 凶}$, Shiddiq Waluyo ${ }^{2}$ \\ Magister Manajemen Universitas Mercu Buana Jakarta \\ ${ }^{1}$ e-mail: gec.information@gmail.com \\ 2 e-mail: waluyo_sidik@yahoo.com
}

\begin{abstract}
This study aims to determine the effect of the delivery of instruction, learning planning, and professional knowledge with mediation of career satisfaction on the performance of the lecturer at Muhammadiyah University Tangerang. The analysis of managerial implications is done by grouping the average value of respondent data for each variable based on demographic data: age, gender, education level, and functional position. The method used in this research was quantitative analysis technique SEM, that was used to determine the effect of instruction delivery variable (X1), learning plan variable (X2), and professional knowledge (X3) with the mediation variable of career satisfaction (Y) on lecturer performance (Z). Data analysis used SEM with the overall test ( $F$-test). The results showed there was positive and significant influence of delivery of instructions variable toward career satisfaction and there was also positive and significant influence of career satisfaction variable to the performance of lecturers.
\end{abstract}

Keywords: lecturer performance, instructional delivery, learning planning, professional knowledge, career satisfaction

\begin{abstract}
Abstrak
Penelitian ini bertujuan untuk mengetahui pengaruh penyampaian instruksi, perencanaan pembelajaran, dan pengetahuan yang profesional dengan mediasi kepuasan akan karier terhadap kinerja dosen pada Universitas Muhammadiyah Tangerang. Analisis dilakukan dengan mengelompokkan nilai rata-rata tiap variabel berdasarkan data demografi: usia, jenis kelamin, tingkat pendidikan dan jabatan fungsional. Metode penelitian yang digunakan adalah kuantitatif dengan teknik analisis SEM, digunakan untuk mengetahui pengaruh antara variabel penyampaian instruksi (X1), variabel perencanaan pembelajaran (X2), dan pengetahuan yang profesional (X3) dengan variabel mediasi kepuasan akan karier (Y) terhadap kinerja dosen (Z). Analisis data menggunakan Structural Equation Modeling (SEM) dengan uji secara keseluruhan (uji F). Hasil penelitian menunjukkan bahwa penyampaian instruksi berpengaruh positif dan signifikan terhadap kepuasan akan karir, dan kepuasan karir berpengaruh signifikan terhadap kinerja dosen.
\end{abstract}

Kata kunci: kinerja dosen, penyampaian instruksi, perencanaan pembelajaran, pengetahuan yang profesional, kepuasan akan karir 


\section{PENDAHULUAN}

Universitas Muhammadiyah Tangerang (UMT) memiliki tanggung jawab yang sangat besar dalam membina dan meningkatkan kinerja para dosennya. Perguruan Tinggi dituntut untuk mampu meningkatkan kinerja dosennya sehingga mampu merencanakan dan melaksanakan serta peningkatan proses tridarma perguruan tinggi, yaitu bidang pengajaran, penelitian, dan pengabdian masyarakat dengan memanfaatkan potensi sumber daya yang ada, agar dapat meningkatkan kompetensi mahasiswa secara keseluruhan dan pemangku kepentingan.

Berdasarkan wawancara kepada beberapa pejabat UMT yang dilakukan pada tanggal sembilan (9) bulan Maret tahun dua ribu lima belas, diketahui bahwa kinerja dosen UMT masih relatif rendah, hal tersebut dievaluasi dari beberapa faktor di antaranya adalah faktor disiplin waktu, hasil karya ilmiah dosen dan mahasiswa. Lebih lanjut diketahui bahwa cara meningkatkan kinerja dosen adalah dengan meningkatkan mutu perencanaan pembelajaran, penyampaian instruksi dan pengetahuan yang profesional melalui frekuensi pelatihan, seminar, studi lanjut, sehingga mahasiswa lebih dapat memahami dan dapat meningkatkan tingkat kepuasan dosen yang pada akhirnya dapat meningkatkan kinerja dosen.

Berdasarkan latar belakang tersebut di atas maka penulis dapat mengidentifikasi permasalahan sebagai berikut: 1) Kurangnya pelatihan tentang penyampaian instruksi sehingga mempengaruhi kepuasan akan karir dosen. 2) Belum optimalnya pelatihan tentang penyampaian instruksi sehingga mempengaruhi kinerja dosen. 3) Perlu ditingkatkan pelatihan tentang perencanaan pembelajaran sehingga mempengaruhi kepuasan karir dosen. 4) Perlu ditingkatkan pelatihan tentang perencanaan pembelajaran sehingga mempengaruhi kinerja dosen. 5) Kurangnya transfer of knowledge tentang pengetahuan yang profesional sehingga mempengaruhi kepuasan karir dosen. 6) Kurangnya transfer of knowledge tentang pengetahuan yang profesional sehingga mempengaruhi kinerja dosen. 7) Perlu ditingkatkan tingkat kepuasan akan karir dosen sehingga mempengaruhi kinerja dosen

Tujuan penelitian ini adalah sebagai berikut: 1) Menganalisis pengaruh Penyampaian Instruksi terhadap Kepuasan Karir,2)Menganalisis pengaruh Penyampaian Instruksi terhadap Kinerja Dosen, 3) Menganalisis pengaruh Perencanaan Pembelajaran terhadap Kepuasan Karir, 4) Menganalisis pengaruh Perencanaan Pembelajaran terhadap Kinerja Dosen, 5) Menganalisis pengaruh Pengetahuan yang Profesional terhadap Kepuasan Karir, 6) Menganalisis pengaruh Pengetahuan yang Profesional terhadap Kinerja Dosen, 7) Menganalisis pengaruh Kepuasan Karir terhadap Kinerja Dosen.

\section{TINJAUAN PUSTAKA}

\section{Kinerja Dosen}

Menurut Maharjan (2012), kinerja adalah suatu hasil yang dicapai karena termotivasi dengan pekerjaan dan puas dengan pekerjaan yang mereka lakukan. Tiap individu cenderung akan dihadapkan pada hal-hal yang mungkin tidak diduga sebelumnya di dalam proses mencapai kebutuhan yang diinginkan sehingga melalui bekerja dan pertumbuhan pengalaman, seseorang akan memperoleh kemajuan dalam hidupnya. Yualina dan Suhana (2012) dalam Astuti dan Dharmadiaksa (2014) kinerja merupakan tingkat keberhasilan yang dicapai oleh seseorang dalam melaksanakan tugas yang dibandingkan dengan standar kerja atau kriteria yang telah ditentukan dan disepakati sebelumnya. Jenis tugas atau posisi merupakan salah satu faktor eksternal yang kuat yang sangat mempengaruhi tindakan seseorang, motivasi kerja dan kepuasan. 
Setiap persyaratan seseorang atau antisipasi pada dasarnya membuat peningkatan hasil kepuasan subyektif atau tekanan, khawatir atau masalah biologis.

\section{Penyampaian Instruksi}

Dalam proses pembelajaran, guru dan siswa merupakan dua komponen yang saling terkait. Antara dua komponen tersebut harus terjalin interaksi yang saling menunjang agar hasil belajar siswa dapat tercapai secara optimal. Guru/dosen secara efektif melibatkan para mahasiswa dalam belajar dengan menggunakan berbagai strategi pembelajaran dalam rangka memenuhi kebutuhan belajar individual, hal ini dijelaskan dalam Sarbeng (2013) dalam penelitian "Staff training and development interventions and teaching performance" Menurut Isaac Baafi (2013) Penyampaian Instruksional adalah proses di mana guru/ dosen menerapkan strategi pembelajaran untuk berkomunikasi dan berinteraksi dengan mahasiswa di seluruh konten akademis dan untuk mendukung keterlibatan mahasiswa.

Elemen kunci penelitian yang didukung pengiriman instruksional yang efektif meliputi sebagai berikut: elemen kunci penelitian yang didukung dari efektif instruksional pengiriman diferensiasi guru/dosen menggunakan beberapa cara instruksional, kegiatan, strategi, dan teknik penilaian untuk memenuhi kebutuhan mahasiswa dan memaksimalkan belajar dari semua mahasiswa. Ragam guru/ dosen menerapkan berbagai teknik kelas, dan strategi juga meningkatkan motivasi mahasiswa dan mengurangi masalah disiplin. Tantangan kognitif guru/dosen memberikan penjelasan mendalam dari konten akademik dan mencakup konsep tingkat tinggi dan keterampilan. Keterlibatan mahasiswa dan dosen adalah mendukung dan gigih dalam menjaga mahasiswa pada tugas dan mendorong mereka untuk secara aktif mengintegrasikan informasi baru dengan pola pembelajaran.

\section{Pengetahuan Profesional}

Dalam buku Kunandar (2007) yang berjudul "Guru Profesional Implementasi Kurikulum Tingkat Satuan Pendidikan" disebutkan bahwa profesionalisme berasal dari kata profesi yang artinya suatu bidang pekerjaan yang ingin atau akan ditekuni oleh seseorang. Menurut Barizi (2009) ada tiga pokok yang harus melekat pada profesional yang baik mengenai etos dalam kerjanya yaitu yang pertama adalah keinginan untuk menjunjung tinggi mutu pekerjaan (job quality). Kedua, menjaga harga diri dalam melaksanakan pekerjaan. Ketiga, keinginan untuk memberikan layanan kepada masyarakat melalui karya profesionalnya. Keempat, dedikasi pada profesi (dedication) dicerminkan dari dedikasi profesional dengan menggunakan pengetahuan dan kecakapan yang dimiliki. Keteguhan tetap untuk melaksanakan pekerjaan meskipun imbalan ekstrinsik dipandang berkurang. Sikap ini merupakan ekspresi dari pencurahan diri yang total terhadap pekerjaan. Pekerjaan didefinisikan sebagai tujuan. Totalitas ini sudah menjadi komitmen pribadi, sehingga kompensasi utama yang diharapkan dari pekerjaan adalah kepuasan ruhani dan setelah itu baru materi. Kelima, kewajiban sosial (social obligation) merupakan pandangan tentang pentingnya profesi serta manfaat yang diperoleh baik oleh masyarakat maupun profesional karena adanya pekerjaan tersebut. Kelima pengertian di atas merupakan kriteria yang digunakan untuk mengukur derajat sikap profesional seseorang. Berdasarkan definisi tersebut maka profesionalisme adalah konsepsi yang mengacu pada sikap seseorang atau bahkan bisa kelompok, yang berhasil memenuhi unsur-unsur tersebut secara sempurna. 


\section{Perencanaan Pembelajaran}

Menurut Kamus Besar Bahasa Indonesia, perencanaan adalah proses, cara, perbuatan merencanakan (merancangkan), sementara pembelajaran adalah proses, cara, perbuatan menjadikan orang atau makhluk hidup belajar. Majid (2007) mengemukakan bahwa perencanaan adalah menyusun langkah-langkah yang akan dilaksanakan untuk mencapai tujuan yang telah ditentukan. Pendapat tersebut menggambarkan bahwa suatu perencanaan diawali dengan penetapan target, selanjutnya dipikirkan bagaimana cara mencapainya. Sejalan dengan pendapat di atas kerangka kerja manajemen pendidikan adalah bertolak dari prinsip suatu organisasi yang dibangun untuk mencapai tujuan tertentu dengan sejumlah aktivitas. Tujuan pengelolaan manajemen pendidikan adalah memaksimalkan pencapaian tujuan sekolah dan perguruan tinggi. Hal ini penting untuk dicapai agar fungsi kelembagaannya menjadi efektif. Gamage dan Pang dalam Syafaruddin (2011) menyebutkan bahwa tujuan manajemen pendidikan adalah sebagai berikut: 1) Mewujudkan pengembangan visi dan sasaran yang ditetapkan. 2) Mengarahkan pengembangan strategi dan rencana untuk mencapaitujuan. 3) Membangun danmengkoordinasikan struktur untuk menjalankan program. 4) Mengelola sumberdaya untuk mendukung organisasi dan programnya. 5) Menghadirkan organisasi dalam target lokal dan masyarakat. 6) Menilai efektivitas dan efisiensi pelaksanaan program.

Menurut Degeng sebagaimana dikutip oleh Uno (2008) dijelaskan bahwa pembelajaran dan pengajaran adalah upaya untuk membelajarkan siswa. Dalam pengertian tersebut di atas terlihat bahwa dalam pembelajaran terdapat kegiatan memilih, menetapkan, mengembangkan metode untuk mencapai hasil pembelajaran yang diinginkan. Kegiatan ini pada dasarnya merupakan inti dari perencanaan pembelajaran. Perencanaan pembelajaran yang disusun oleh guru dituangkan dalam perangkat perencanaan pembelajaran yang meliputi silabus dan rencana pelaksanaan pembelajaran. Dengan asumsi gurulah yang paling tahu mengenai tingkat perkembangan siswa, perbedaan siswa, daya serap, suasana dalam kegiatan pembelajaran, serta sarana dan sumber yang tersedia. Sebagaimana yang dikutip oleh Majid (2007) dari Kenneth D. Moore, mengemukakan bahwa rencana pelaksanaan pembelajaran yang baik hendaknya memuat aspek-aspek sebagai berikut: topik bahasan, tujuan pembelajaran (kompetensi dan indikator kompetensi), materi pelajaran, kegiatan pembelajaran, alat/media yang dibutuhkan, dan evaluasi hasil belajar.

\section{Kepuasan Karir}

Dalam buku Munandar (2010) yang berjudul Psikologi Industri, terdapat beberapa teori-teori kepuasan kerja, yaitu:

1. Teori Pertentangan (disperancy theory). Teori dari Locke menyatakan bahwa kepuasan atau ketidakpuasan terhadap beberapa aspek dari pekerjaan mencerminkan penimbangan dua nilai: pertentangan yang dipersepsikan antara apa yang diinginkan seseorang individu dengan apa yang ia terima, pentingnya apa yang diinginkan bagi individu. Kepuasan kerja secara keseluruhan bagi seorang individu adalah jumah dari kepuasan kerja dari setiap aspek pekerjaan dikalikan dengan derajat pentingnya aspek pekerjaan bagi individu. Menurut Locke, seorang individu akan merasa puas atau tidak puas merupakan sesuatu yang pribadi, tergantung bagaimana ia mempersepsikan adanya kesesuaian atau pertentangan antara keinginankeinginannya dan hasil keluarannya.

2. Model dari Kepuasan Bidang (facet satisfaction). Model Lawler dari kepuasan bidang berkaitan erat dengan 
teori keadilan dari Adams. Menurut model Lawler orang akan puas dengan bidang tertentu dari pekerjaan mereka (misalnya dengan rekan kerja, atasan, gaji) jika jumlah dari bidang mereka persepsikan harus mereka terima untuk melaksanakan kerja mereka sama dengan jumlah yang mereka persepsikan dari yang secara aktual mereka terima.

3. Teori Proses-Bertentangan (oppon-entprocess theory). Teori proses-bertentangandariLandymemandangkepuasan kerja dari perspektif yang berbeda secara mendasar daripada pendekatan yang lain. Teori ini menekankan bahwa orang ingin mempertahankan suatu keseimbangan emosional (emotional equilibrium). Teori proses bertentangan mengasumsikan bahwa kondisi emosional yang ekstrim tidak memberikan kemaslahatan. Kepuasan atau ketidakpuasan kerja (dengan emosi yang berhubungan) memacu mekanisme fisiologikal dalam sistem pusat syaraf yang membuat aktif emosi yang bertentangan atau berlawanan.

\section{METODE PENELITIAN}

\section{Desain Penelitian}

Desain penelitian ini adalah analisis yang berhubungan dengan tujuan penelitian untuk menganalisis pengaruh suatu variabel terhadap variabel lain, yaitu penyampaian instruksi (delivery), perencanaan pembelajaran (planning), pengetahuan yang profesional (knowledge), dan kepuasan akan karir (satisfaction) terhadap kinerja dosen (performance) UMT. Melalui rancangan ini, diharapkan dapat mempermudah dalam melakukan penelusuran dan pengukuran berbagai indikator yang behubungan dengan variabel-variabel yang sedang diteliti. Menurut (Malhotra, 2007) Desain penelitian memberikan prosedur untuk mendapatkan informasi yang diperlukan untuk menyusun atau menyelesaikan masalah dalam penelitian. Desain penelitian merupakan dasar dalam melakukan penelitian yang merupakan rancangan umum tentang metode-metode dan prosedur-prosedur untuk mengumpulkan dan menganilisis informasi yang dibutuhkan. Hal ini menjelaskan bahwa suatu penelitian diharapkan memenuhi tahapan dan metode yang tepat sesuai dengan model yang ingin diungkap.

Tipe penelitian ini adalah penelitian penjelasan (explanatory research), karena penelitian ini bermaksud menjelaskan pengaruh/hubungan antar model. Penelitian ini bertujuan untuk menguji kebenaran suatu hipotesis yang dilaksanakan melalui pengumpulan data di lapangan, di mana dalam penelitian ini akan mengungkapkan hubungan sebab dan akibat (cause and effect relationship). Dalam penelitian ini akan dilakukan pengujian tentang pengaruh penyampaian instruksi, perencanaan pembelajaran, dan pengetahuan yang profesional dengan mediasi kepuasan akan karir terhadap kinerja dosen. 
Tabel 1. Definisi Operasional Variabel

Variabel dan Definisi
Penyampaian Instruksi
(X1).
Teori Sarbeng (2013)
yang menyatakan bahwa
guru/dosen secara efek-
tif melibatkan para ma-
hasiswa dalam belajar
dengan menggunakan
berbagai strategi pem-
belajaran dalam rangka
memenuhi kebutuhan be-
lajar individual.

Student

Engagement

\section{Teknik \\ Penyampaian}

\section{Efektivitas} penyampaian

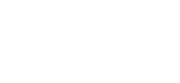


Perencanaan Pembelajaran (X3).

Strategi
Pembelajaran

Teori dari Majid (2007) yang menyatakan bahwa perencanaan adalah menyusun langkah-langkah yang akan dilaksanakan untuk mencapai tujuan yang telah ditentukan.

Sumber daya
Rencana

Organisasi kepuasan kerja adalah sebagai suatu sikap umum seorang individu terhadap pekerjaannya. Hal berarti penilaian (assesment) seorang pegawai terhadap puas atau tidak puasnya dia terhadap pekerjaan merupakan penjumlahan yang rumit dari sejumlah unsur pekerjaan yang diskrit (terbedakan dan terpisahkan satu sama lain).

\section{Kinerja Dosen (Z). Teori dari Maharjan (2012) yang menyatakan bahwa kinerja adalah suatu hasil yang dicapai karena termotivasi den- gan pekerjaan dan puas dengan pekerjaan yang mereka lakukan.}

1. Kemampuan membuat rencana pembelajaran.

2. Kemampuan mengatur waktu untuk membuat materi pembelajaran.

1. Kememampuan menyeimbangkan obyek pembelajaran dengan kebutuhan mahasiswa.

2. Kemampuan untuk mengatur fasilitas pembelajaran.

1. Kemampuan membuat rencana sesuai dengan organisasi.

2. Kemampuan untuk membuat rencara akses kurikulum untuk mahasiswa di kelas.

1. Apakah puas dengan karir sekarang.

Likert/

Ordinal

2. Apakah tujuan yang saat ini sudah sesuai dengan yang direncanakan.

15

16
1. Apakah sudah mendapatkan 23 training yang cukup.
2. Apakah sudah mendapat kesem- 24 patan training.
3. Apakah sudah mendapatkan ja- 25 batan yang sesuai
1. Apakah pekerjaan sekarang su- dah mencapai harapan.
Harapan dalam berkarir
maju

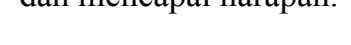

\begin{tabular}{lll}
$\begin{array}{l}\text { Kualitas } \\
\text { Hasil Kerja }\end{array}$ & $\begin{array}{l}\text { 1. Kesesuaian materi dengan sila- } \\
\text { bus. }\end{array}$ & $\begin{array}{l}\text { Likert/ } \\
\text { Ordinal }\end{array}$ \\
$\begin{array}{l}\text { 2. Penguasahaan materi perkulia- } \\
\text { han. }\end{array}$ & 27 \\
$\begin{array}{l}\text { Kuantitas hasil } \\
\text { kerja }\end{array}$ & $\begin{array}{l}\text { 1. Tingkat penyerapan materi ma- } \\
\text { hasiswa. }\end{array}$ & 29 \\
$\begin{array}{l}\text { 2. Tingkat kelulusan mahasiswa. } \\
\text { Ketepatan waktu } \\
\text { hasil }\end{array}$ & $\begin{array}{l}\text { 1. Ketepatan kelulusan mahasiswa. } \\
\text { 2. Hasil karya ilmiah dalam satu } \\
\text { semester. }\end{array}$ & 30 \\
\hline
\end{tabular}

6




\section{Populasi dan Sampel Penelitian Populasi}

Menurut Ghozali, I. \& Fuad (2008), beberapa pedoman penentuan besarnya sampel untuk SEM diberikan sebagai berikut:

1. Bila pendugaan parameter menggunakan metode kemungkinan maksimum (maximum likelihood estimation) besar sampel yang disarankan adalah antara 100 hingga 200, dengan minimum sampel adalah 50 .

2. Sebanyak 5 hingga 10 kali jumlah parameter yang ada di dalam model.

3. Sama dengan 5 hingga 10 kali jumlah variabel manifest (indikator) dari keseluruhan variabel laten.

Pada penelitian ini melibatkan sebanyak 32 indikator, sehingga merujuk pada aturan ketiga diperlukan ukuran sampel minimal 5x32 atau sebesar 160 .

\section{Jenis dan Sumber Data}

Sumber data untuk varibel bebas, tidak bebas, dan intervining adalah data primer dengan cara menyebarkan kuesioner kepada dosen UMT dengan skala likert/ ordinal. Data sekunder dikumpulkan dari literatur, jurnal, dan sumber-sumber lain yang mendukung penelitian ini.

\section{Teknik Pengumpulan Data}

Kuisioner disusun dan dikembangkan berdasarkan deskripsi teori yang ada melalui butir pertanyaan mengenai karakteristik responden dan pernyataan tentang variabel yang akan diteliti. Untuk mengungkap variabel yang akan diteliti, kuisioner yang disusun disesuaikan dengan sub variabel penelitian serta indikator variabel yang akan ditetapkan berdasarkan konsep teori sehingga jumlah pernyataan dalam kuisioner sesuai dengan jumlah indikator variabel yang ada. Dalam butir pernyataan terdapat beberapa alternatif jawaban yang tersedia dengan skala likert yaitu menggunakan 5 tingkat skala sesuai jawaban, yaitu:
1: Sangat setuju/Selalu diberi skor 5,

2: Setuju/Sering diberi skor 4,

3: Ragu-ragu/Kadang-kadang diberi skor 3,

4: Tidak Setuju/Hampir tidak Pernah diberi skor 2,

5: Sangat Tidak Setuju/Tidak Pernah diberi skor 1.

\section{Teknik Analisis Data}

Penelitian ini menggunakan SEM (Structural Equation Model), dengan mengacu pada tujuan penelitian maka data analisis yang digunakan dalam penelitian ini adalah SEM (Structural Equation Modelling) dengan program software LISREL (Linier Structural Relationship) 8,70. Menurut Bollen dan Long (1993) dalam Latan (2013) terdapat lima proses yang harus dilalui dalam analisa CB-SEM (covariance-based structural equation modeling), dimana setiap tahapan akan berpengaruh terhadap tahapan selanjutnya, yaitu (1) spesifikasi model, (2) identifikasi model, (3) estimasi model, (4) evaluasi model, dan (5) respesifikasi model seperti tampak pada gambar 4.4 di bawah ini:

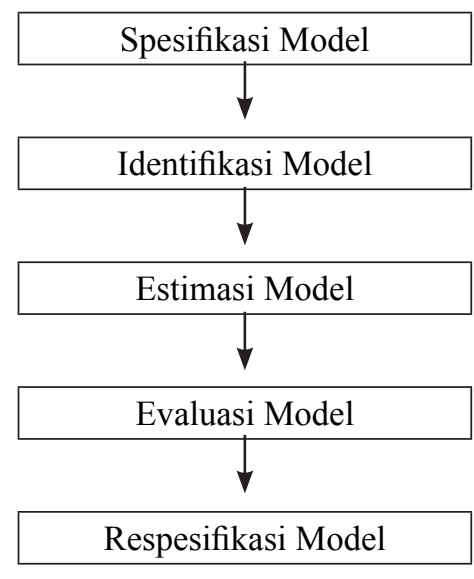

\section{Gambar 1. Tahapan Analisis} Menggunakan CB-SEM

Sumber:Diadopsi dari Bollen dan Long (1993) dalam Latan (2013) 


\section{HASIL DAN PEMBAHASAN}

\section{Hasil Penelitian.}

Uji validitas convergent dengan program LISREL dapat dilihat dari nilai loading factor untuk tiap indikator konstruk. Nilai loading factor yang tinggi menunjukkan bahwa tiap indikator konstruk converge pada satu titik. Rule oh thumb yang biasanya digunakan untuk menilai validitas convergent yaitu nilai loading factor harus lebih dari 0,7 untuk penelitian yang bersifat confirmatory dan nilai average variance extracted (AVE) harus lebih besar dari 0,5. Uji realibilitas dilakukan untuk membuktikan akurasi, konsistensi, dan ketepatan instrumen dalam mengukur konstruk. Dalam CBSEM dengan menggunakan LISREL, untuk mengukur reliabilitas suatu konstruk dapat dilakukan dengan dua cara yaitu dengan Cronbach's alpha dan composite reliability.

Tabel 2. Ringkasan Rule of Thumb Uji Validitas dan Uji Reliabilitas

\begin{tabular}{|c|c|c|}
\hline $\begin{array}{l}\text { Valilidas dan } \\
\text { Reliabilitas }\end{array}$ & Parameter & $\begin{array}{l}\text { Rule of } \\
\text { Thumb }\end{array}$ \\
\hline $\begin{array}{l}\text { Va l i d it a s } \\
\text { Convergent }\end{array}$ & $\begin{array}{l}\text { Loading Factor } \\
\text { Average Vari- } \\
\text { ance Extrated } \\
(\text { AVE })\end{array}$ & $\begin{array}{l}>0,7 \text { untuk } \\
\text { Confirmatory } \\
\text { Research } \\
>0,5 \text { untuk } \\
\text { Confirmatory } \\
\text { Research }\end{array}$ \\
\hline $\begin{array}{l}\text { Validitas } \\
\text { Discriminant }\end{array}$ & $\begin{array}{l}\text { Cross Loading } \\
\text { Akar kuadrat } \\
\text { AVE dan korela- } \\
\text { si antar konstruk } \\
\text { Laten }\end{array}$ & $\begin{array}{l}\text { I n d i k a t o r } \\
\text { loading > se- } \\
\text { luruh Cross } \\
\text { Loading } \\
\text { Akar kuadrat } \\
\text { AVE > Kore- } \\
\text { lasi antar kon- } \\
\text { struk Laten }\end{array}$ \\
\hline Reliabilitas & $\begin{array}{l}\text { Cronbach's Al- } \\
\text { pha } \\
\text { Composite Reli- } \\
\text { ability }\end{array}$ & $\begin{array}{l}>0,7 \text { untuk } \\
\text { Confirmatory } \\
\text { Research } \\
>0,7 \text { untuk } \\
\text { Confirmatory } \\
\text { Research }\end{array}$ \\
\hline
\end{tabular}

Sumber : Diolah dari berbagai literatur
Menilai kelayakan Model (Goodness of Fit)

Tabel 3. Ringkasan Goodness of Fit

\begin{tabular}{|c|c|c|}
\hline No & Goodness of Fit & Cut-off Value \\
\hline 1 & $\begin{array}{l}\text { Adjusted Goodness of } \\
\text { Fit Index (AGFI) }\end{array}$ & $\geq 0.90$ \\
\hline 2 & $\begin{array}{l}\text { Akaike Information } \\
\text { Index (AIC) }\end{array}$ & $\begin{array}{l}<\text { AIC Saturated } \\
\text { dan Indepen- } \\
\text { dence Model }\end{array}$ \\
\hline 3 & Chi Square & Diharapkan kecil \\
\hline 4 & $\begin{array}{l}\text { Comparative Fit Index } \\
(\mathrm{CFI})\end{array}$ & $>0.90,>0.95$ \\
\hline 5 & $\begin{array}{l}\text { Consintent Akaike } \\
\text { Information Index } \\
\text { (CAIC) }\end{array}$ & $\begin{array}{l}\text { < CAIC Saturat- } \\
\text { ed dan Indepen- } \\
\text { dence Model }\end{array}$ \\
\hline 6 & Degree of Freedom & Diharapkan besar \\
\hline 7 & $\begin{array}{l}\text { Expected Cross Valida- } \\
\text { tion Index (ECVI) }\end{array}$ & $\begin{array}{l}<\text { ECVI Saturat- } \\
\text { ed dan Indepen- } \\
\text { dence Model }\end{array}$ \\
\hline 8 & $\begin{array}{l}\text { Goodness of Fit Index } \\
\text { (GFI) }\end{array}$ & $>0.90$ \\
\hline 9 & $\begin{array}{l}\text { Incremental Fit Index } \\
\text { (IFI) }\end{array}$ & $>0.90,>0.95$ \\
\hline 10 & $\begin{array}{l}\text { Non-Centrality Param- } \\
\text { eter }(\mathrm{NCP})\end{array}$ & $\begin{array}{l}<\text { Independence } \\
\text { Model }\end{array}$ \\
\hline 11 & $\begin{array}{l}\text { Normed Fit Index } \\
(\mathrm{NFI})\end{array}$ & $>0.90,>0.95$ \\
\hline 12 & $\begin{array}{l}\text { Parsimonius Normed } \\
\text { Fit Index (PNFI) }\end{array}$ & $0.06-0.09$ \\
\hline 13 & $\begin{array}{l}\text { Parsimonious Good- } \\
\text { ness of Fit Index } \\
\text { (FGFI) }\end{array}$ & $>0.60$ \\
\hline 14 & Probability & $\geq 0.05$ \\
\hline 15 & P Value for RMSEA & $>0.05$ \\
\hline 16 & $\begin{array}{l}\text { Relative Fit Index } \\
\text { (RFI) }\end{array}$ & $>0.90,>0.95$ \\
\hline 17 & $\begin{array}{l}\text { Root Mean Square } \\
\text { Error Approximation } \\
\text { (RMSEA) }\end{array}$ & $0.05-0.08$ \\
\hline 18 & $\begin{array}{l}\text { Root Mean Square } \\
\text { Residual (RMSR) }\end{array}$ & $<0.08$ \\
\hline
\end{tabular}

Sumber: Latan (2012) 
Goodness offit merupakan indikasi dari perbandingan antara model yang dispesifikasi dengan matriks kovarian antar indikator atau observed variabel. Jika Goodness of fit yang dihasilkan suatu model itu baik, maka model tersebut dapat diterima dan sebaliknya jika goodness of fit yang dihasilkan suatu model itu buruk, maka model tersebut harus ditolak. Secara keseluruhan terdapat tiga jenis ukuran Goodness of fit yaitu (1) absolute fit indices; (2) incremental fit indices; (3) parsimony fit indices. Menurut Hair et. al (1998) dalam Ghozali (2011) penggunaan 4-5 kriteria goodness of fit dianggap sudah mencukupi untuk menilai kelayakan suatu model, asalkan masing-masing kriteria dari goodness of fit yaitu absolute fit indices, incremental, absolte fit indices terwakili.

Pada output di atas dapat dilihat nilai t hitung pada masing masing indikator telah signifikan $(t>1,96)$ sehingga pengujian dapat dilanjutkan. Hasil tersebut menunjukkan bahwa indikator-indikator mampu membentuk konstruk-konstruk.

\section{Uji Persyaratan Statistik}

Berikut adalah hasil estimasi persyaratan statistik yang diperlukan pada SEM dengan menggunakan Lisrel 8.7.

Tabel 4. Uji Good of Fit

\begin{tabular}{lccc}
\hline \multicolumn{1}{c}{ Uji Good of Fit } & Good Fit & Hasil & Kesimpulan \\
\hline Normed Fit Index (NFI) & $>0,90,>0,95$ & 0,91 & Good Fit \\
Non-Normed Fit Index (NNFI) & $>0,90,>0,95$ & 0,95 & Good Fit \\
Parsimonius Normed Fit Index (PNFI) & $0.06-0,09$ & 0,76 & Good Fit \\
Comparative Fit Index (CFI) & $>0,90,>0,95$ & 0,96 & Good Fit \\
Incremental Fit Index (IFI) & $>0,90,>0,95$ & 0,96 & Good Fit \\
Relative Fit Index (RFI) & $>0,90,>0,95$ & 0,90 & Good Fit \\
Root Mean Square Error of Approximation (RMSEA) & $0,05-0,08$ & 0,063 & Good Fit \\
\hline
\end{tabular}

Sumber: Pengolahan Data Lisrel 8,70 (2015)

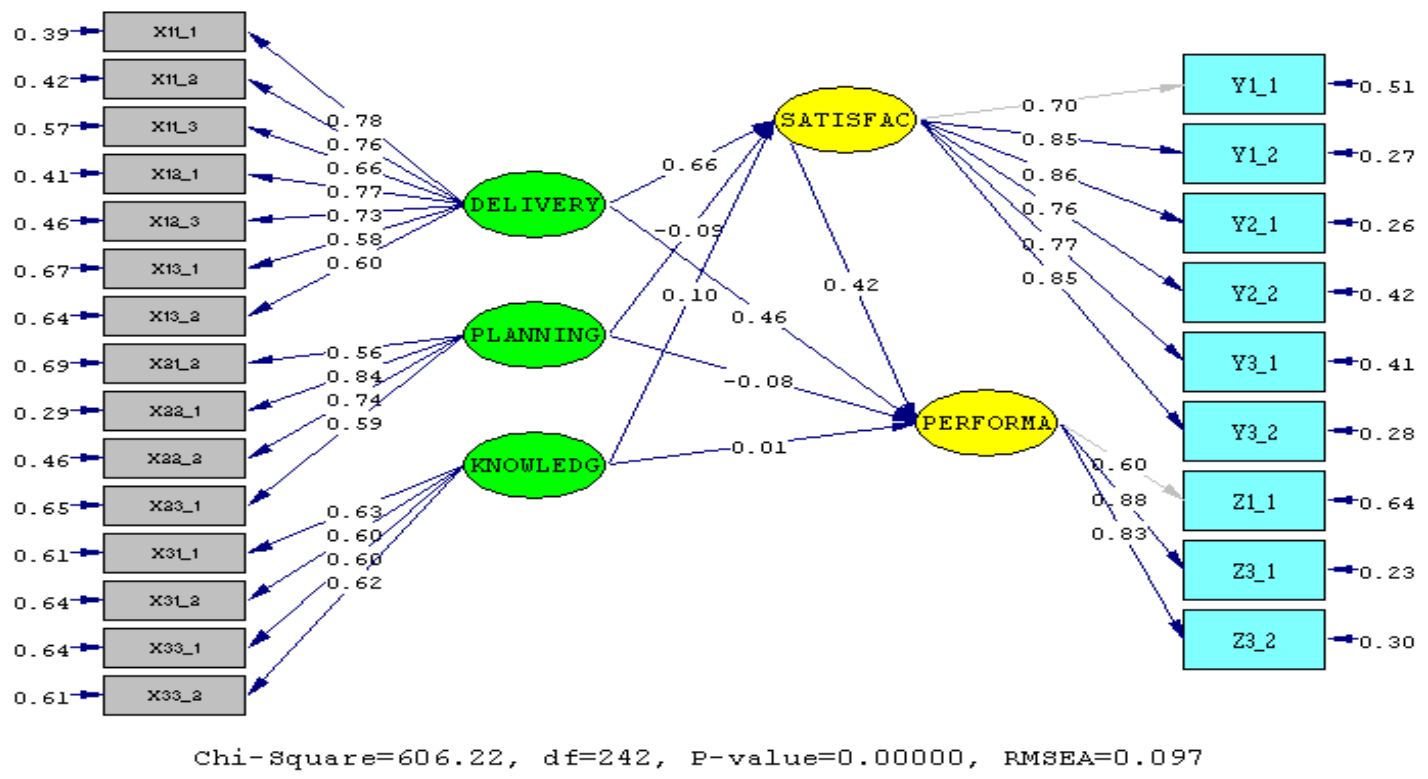

Gambar 2. CFA Full Model SEM

Sumber: Pengolahan data Lisrel 8,70 (2015) 
Berdasarkan uji persyaratan statistik di atas maka model dinyatakan fit dan pengujian hipotesis dapat dilakukan.

\section{Persamaan Struktural}

Langkah berikutnya adalah melakukan run untuk Full Model SEM, ini dilakukan sampai kriteria fit model tercapai sebagai mana terlihat pada gambar 2 .

\section{Persamaan Model Pengukuran}

Persamaan model pengukuran dibentuk dari loading factor dan variance error pada masing-masing indikator terhadap konstruk yang dibentuknya. Sebagaimana dalam lampiran output estimate/maximum likehood yang menunjukkan persamaan model pengukuran sebagai berikut: Pada hasil output di atas dapat dilihat nilai t hitung pada masing masing indikator telah signifikan. Untuk Y1.1 sebesar 7,64>1,96, Y1.2 sebesar 5,52>1,96, Y2.1 sebesar 6,75>1,96, Y2.2 sebesar 8,55>1,96, Y3.1 sebesar 8,64>1,96, Y3.2 sebesar 6,73>1,96, Z1.1 sebesar 7,61>1,96, Z3.1 sebesar 4,93>1,96, Z3.2 sebesar 5,70>1,96, X11.1 sebesar 6,7>1,96, X11.2 sebesar 7,57>1,96, X11.3 sebesar
8,26>1,96, X12.1 sebesar 7,37>1,96, $\mathrm{X} 12.3>1,96, \mathrm{X} 13.1$ sebesar 8,49>1,96, X13.2 sebesar 8,11>1,96, X22.2 sebesar 6,67>1,96, X23.1 sebesar 8,27>1,96, X31.1 sebesar 7,23>1,96, X31.2 sebesar 7,42>1,96, X33.1 sebesar 6,32>1,96 dan X33.2 sebesar $5,73>1,96$. Hasil tersebut menunjukkan bahwa indikator-indikator di atas sudah fit dan modelnya sudah baik.

\section{Pengujian Hipotesis}

Pengujian Hipotesis model Full SEM t hitung dapat dilihat pada gambar 3 .

\section{Analisis Hipotesis}

$\mathrm{H} 1$ : terbukti diterima karena variabel $d e-$ livery berpengaruh signifikan terhadap variabel satisfaction karena t-statistik $7,14>1,96$.

$\mathrm{H} 2$ : terbukti diterima karena variabel delivery berpengaruh signifikan terhadap variabel performance dengan $\mathrm{t}$-statistik 3,95>1,96

H3: ditolak karena variabel Planning tidak berpengaruh terhadap variabel satisfaction $\mathrm{t}$-statistik $-1,06<1,96$

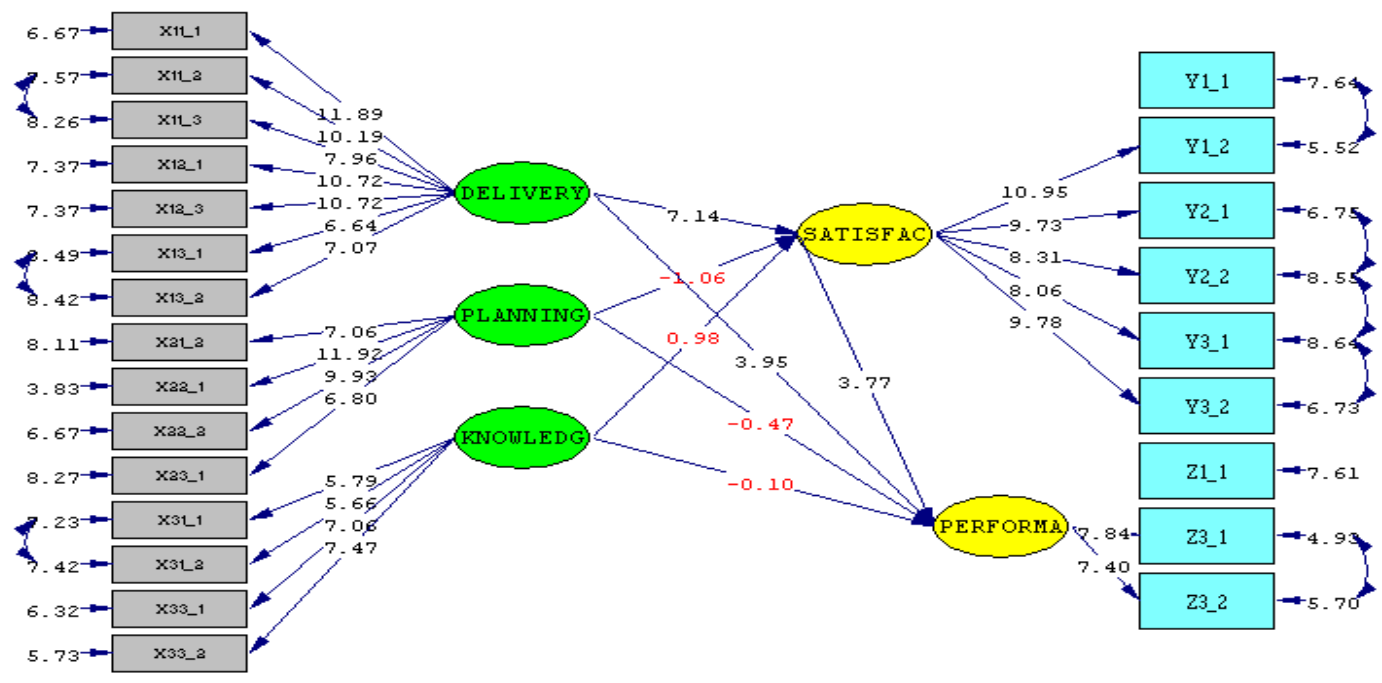

Chi-square $=373.77, \mathrm{~d} f=229, \mathrm{P}-\mathrm{value}=0.00000$, RMSEA $=0.063$

Gambar 3. CFA Full Model SEM t Hitung

Sumber: Pengolahan data Lisrel 8,70 (2015) 
H4 ditolak karena variabel planning tidak berpengaruh signifikan terhadap variabel performance dengan $\mathrm{t}$ statistik $-0,74<1,96$

H5: ditolak karena variabel knowledge tidak berpengaruh signifikan terhadap variabel satisfaction dengan t statistik $0,98<1,96$

H6: ditolak karena variabel knowledge tidak berpengaruh signifikan terhadap variabel performance dengan $t$ statistik $-0,10<1,96$.

H7: diterima karena variabel satisfaction berpengaruh signifikan terhadap variabel performance dengan $t$ statistik $3,77>1,96$.

\section{SIMPULAN DAN SARAN}

Berdasarkan hasil analisis dan pembahasan pengaruh penyampaian instruksi, perencanaan pembelajaran, dan pengetahuan professional dengan mediasi kepuasan akan karir terhadap kinerja dosen Universitas Muhammadyah Tangerang dapat disimpulkan:

1. Penyampaian instruksi dosen kepada mahasiswa di Universitas Muhammadiyah Tangerang sangat menentukan kepuasan akan karir.

2. Penyampaian instruksi dosen kepada mahasiswa di Universitas Muhammadiyah Tangerang sangat menentukan kinerja dosen.

3. Perencanaan pembelajaran yang dilakukan oleh dosen di Universitas Muhammdiyah Tangerang tidak menentukan kepuasan akan karir.

4. Perencanaan pembelajaran yang dilakukan oleh dosen di Universitas Muhammadiyah Tangerang tidak menentukan kinerja dosen.

5. Pengetahuan yang profesional yang dilakukan oleh dosen di Universitas Muhammadiyah Tangerang tidak menentukan kepuasan akan karir.
6. Pengetahuan yang profesional yang dilakukan oleh dosen di Universitas Muhammadiyah Tangerang tidak menentukan kinerja dosen.

7. Kepuasan akan karir dosen di Universitas Muhammadiyah Tangerang sangat menentukan peningkatan kinerja dosen.

Berdasarkan hasil penelitian ini disimpulkan bahwa penyampaian instruksi berpengaruh signifikan terhadap kepuasan karir dan kinerja dosen sedangkan perencanaan pembelajaran tidak berpengaruh terhadap kepuasan karir dan kinerja dosen. Untuk pengetahuan yang profesional tidak berpengaruh terhadap kepuasan karir dan kinerja dosen sedangkan kepuasan karir berpengaruh signifikan terhadap kinerja dosen. Dengan kesimpulan tersebut maka saran untuk universitas:

1. Universitas harus mempertahankan kemampuan dosen dalam proses penyampaian materi kuliah pada mahasiswa dengan melakukan pelatihan-pelatihan yang terkait. Selain pelatihan, universitas harus menyiapkan perangkat sistem recruitment dengan lebih baik lagi sehingga dosen yang diterima memenuhi kualifikasi yang dibutuhkan.

2. Universitas harus menetapkan standar kualitas dosen dalam rangka menentukan kompensasi, sehingga penilaian terhadap tiap dosen akan menjadi lebih obyektif, sehingga dosen akan puas akan karirnya bekerja sebagai dosen.

3. Meningkatkan kompetensi dosen dalam rangka proses belajar mengajar sehingga mahasiswa mendapatkan materi sesuai dengan yang dibutuhkan dan mengikuti perkembangan ilmu pengetahuan yang terkini. 
Untuk penelitian selanjutnya penulis menyarankan dilakukan penelitian untuk variabel yang lain seperti variabel disiplin sehingga dapat diketahui apakah hasil penelitian sama atau berbeda. Di samping itu dapat menambahkan variabel lain seperti kompetensi berkaitan dengan kondisi dunia pendidikan tinggi yang kompetitif sekarang ini.

\section{REFERENSI}

Astuti dan Dharmadiaksa. 2014. Pengaruh Efektivitas Penerapan Sistem Informasi Akuntansi, Pemanfaatan, dan Kesesuaian Tugas pada Kinerja Karyawan. Jurnal Akuntansi. Universitas Udayana Vol. 9 (2).

Barizi, Ahmad. 2009. Menjadi Guru Unggul Bagaimana Menciptakan Pembelajaran yang Produktif dan Profesional. Yogyakarta: Ar-Ruz Media

Ghozali, I. \& Fuad. 2008. Structural Equation Modeling: Teori, Konsep, dan Aplikasi dengan Program Lisrel 8.80 ( $2^{\text {th }}$ ed.). Semarang: Badan Penerbit Universitas Diponegoro.

Hair, J.F., Jr., et.al. 1998. Multivariate Data Analysis. 5th ed. New Jersey: Prentice-Hall Int'l. Englew ood Cliff.

Kunandar. 2007. Guru Profesional Implementasi Kurikulum Tingkat Satuan Pendidikan (KTSP) dan Persiapan Menghadapi Sertifikasi Guru. Jakarta: PT Raja Grafindo Persada.
Latan, Hengky. 2013. Structural Equation Modelling: Konsep dan Aplikasi Menggunakan Program Lisrel 8.80. Bandung: Penerbit Alfabeta.

Maharjan, S. 2012. Association between Work Motivation and Job Satisfaction of College Teachers. Administrative and Management Review. Vol. 24, (2).

Majid, Abdul. 2007. Perencanaan Pembelajaran. Bandung: Remaja Rosdakarya.

Malhotra. 2007. Marketing Research An Applied Orientation. International Edition: Pearson.

Munandar, 2010. Budgeting, Perencanaan Kerja, Pengkoordinasian Kerja dan Pengawasan Kerja. Yogyakarta: BPFE Universitas Gadjah Mada.

Robbins SP, dan Judge. 2007. Perilaku Organisasi. Jakarta: Salemba Empat.

Sarbeng, Isaac Baafi. 2013. Staff Trainning and Devevopment Interventions and Teaching Performance: Application of Structural Equation Modelling. University of Cape Coast. Cape Coast, Ghana.

Syafaruddin. 2011. Pengelolaan Pendidikan. Medan: Perdana Publishing.

Uno, Hamzah. 2008, Teori Motivasi dan Pengukurannya Analisis di Bidang Pendidikan. Jakarta: Bumi Aksara. 
